\title{
Genetic Variability and Elite Line Selection for High Essential Oil and Nepetalactone Content in Catmint (Nepeta cataria L.)
}

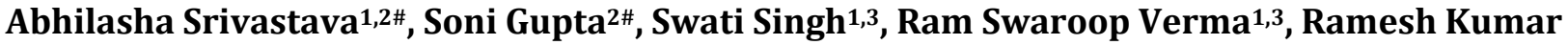 \\ Srivastava ${ }^{1,4}$, Anil Kumar Gupta ${ }^{1,2 *}$, Raj Kishori Lal ${ }^{2}$ \\ ${ }^{1}$ Academy of Scientific and Innovative Research (AcSIR), Ghaziabad, India \\ ${ }^{2}$ Division of Plant Breeding and Genetic Resource Conservation, CSIR—Central Institute of Medicinal and Aromatic Plants, P.O. \\ CIMAP, Lucknow, India \\ ${ }^{3}$ Phytochemistry Division, CSIR-Central Institute of Medicinal and Aromatic Plants, P.O. CIMAP, Lucknow, India \\ ${ }^{4}$ Technology and Business Development Division, CSIR-Central Institute of Medicinal and Aromatic Plants, P.O. CIMAP, \\ Lucknow, India \\ Email: *ak.gupta@cimap.res.in
}

How to cite this paper: Srivastava, A. Gupta, S., Singh, S., Verma, R.S., Srivastava, R.K., Gupta, A.K. and Lal, R.K. (2021) Genetic Variability and Elite Line Selection for High Essential Oil and Nepetalactone Content in Catmint (Nepeta cataria L.). American Journal of Plant Sciences, 12, 1135-1154.

https://doi.org/10.4236/ajps.2021.127079

Received: April 9, 2021

Accepted: July 26, 2021

Published: July 29, 2021

Copyright $\odot 2021$ by author(s) and Scientific Research Publishing Inc. This work is licensed under the Creative Commons Attribution International License (CC BY 4.0)

http://creativecommons.org/licenses/by/4.0/ (c) (i) Open Access

\begin{abstract}
Nepeta cataria L., commonly known as catmint or catnip, belongs to the family "Lamiaceae" and is indigenous to Europe and Asia. The essential oil of this species is known for the richness and diversity of nepetalactones (NPL) which are used as mosquito/insect repellents in perfumery and cosmetic industries. Reports on Indian catmint germplasm are very meager and warrants exploration of its commercial potential as a natural, non-toxic source of insect repellents. With this objective, commercial open-pollinated seeds of catmint collected from its native, temperate habitat in Himalayas were introduced in the tropical plains. Subsequent to adaptation to a new zone we were able to isolate nineteen individual plants based on plant growth. Hydrodistillation of the fresh herb yielded essential oil in the range of $0.01 \%$ to $0.2 \%$. Gas Chromatography (GC) and GC-Mass Spectrometry (GC-MS) analyses of the oil revealed the dominance of monoterpene hydrocarbon, namely, 4aa,7a,7aa NPL (1) isomer (84\%). The other two isomers of nepetalactone, $4 \mathrm{a} \alpha, 7 \alpha, 7 \mathrm{a} \beta$ NPL (2) and 4aa,7 $3,7 \mathrm{a} \alpha$ NPL (3) were also present, although in very less amounts $(1.0 \%$ and $1.6 \%$, respectively). Sesquiterpenes identified were a-humulene (traces), (E)-caryophyllene $(0.6 \%)$ and caryophyllene oxide (1.7\%). We compared the identified Indian catmint chemotype with the other oils from temperate, sub-tropical and tropical locations based on literature
\end{abstract}


search. The Indian chemotype was found to be similar to the oils from $\mathrm{Bu}$ rundi, France, Turkey, UK and USA, mainly due to more accumulation of 4a $a, 7 a, 7 a \alpha$ NPL (1) isomer. These oils grouped together in Principal Component Analysis. Breeding lines are presently being developed to improve yield related traits in this plant. Multidisciplinary R\&D efforts along with setting up industry related guidelines are required to successfully commercialize catmint cultivation. Several species of Nepeta genus have high nepetalactone content too and their potential as a commercial source of these isomers still needs to be explored.

\section{Keywords}

Gas Chromatography-Mass Spectrometry, Genetic Improvement, Half-Sib Selection, Insect Repellent, Principal Component Analysis

\section{Introduction}

The genus Nepeta includes about 275 accepted species found throughout the world [1]. Catmint or catnip (Nepeta cataria L.) is a small aromatic herb and a member of the mint family, Lamiaceae. It is indigenous to Europe and Asia, but over time it has naturalized in many areas around the world including Canada, U.S., Africa, Japan, Korea, and China (Supplementary Figure S1). In India, it is mostly found in the western Himalayan region in Kashmir. Along with several species of Nepeta, Blatter [2], Singh and Kachroo [3], Stewart [4] reported the presence of $N$. cataria in Jammu and Kashmir. Hooker [5], Mukerjee [6], Fernald [7] and Bhatacharjee [8] also reported $N$. cataria along with several other Nepeta $s p$. in different northern regions of India (Punjab and Himachal Pradesh). $N$. cataria grows as a common garden plant or is found in hedges, fence rows, wastelands, roadsides and also can be cultivated easily. The euphoric effect of its essential oil (containing volatile iridoid monoterpenoid nepetalactones) on domestic cats and other feline members is well documented. The glandular trichomes present in the leaf epidermis are the major site of biosynthesis of the aromatic volatiles [9].

As a medicinal herb, the plant finds its use in herbal tea (fever/cold relief, cough suppressant) and for culinary purposes [10]. The oil can also be used in the field of aroma and perfumery [11]. The plant also possesses antioxidant, anti-inflammatory, antimicrobial, antidiabetic, cardioprotective, insecticidal and antiasthmatic properties [12] [13] [14]. They are also used to make insect attractants (pheromone traps). Its essential oil is used as insect and mosquito repellent [15]. The essential oils are rich in bicyclic monoterpenoids called nepetalactone (NPL) that can exist as eight possible stereoisomers, out of which six have been found in nature [16]. The predominant stereoisomers in $N$. cataria oil are 4a $a, 7 \alpha, 7 a \alpha$ NPL (Z,E-nepetalactone) (1) and 4aa,7a,7a $\beta$ NPL (E,Z-nepetalactone) (2) and the isomer which is cat attractant is the 
4aa,7a,7a a NPL (1) [17]. The (Z,E)-nepetalactone (1) can be hydrogenated to dihydro-nepetalactone for its use as repellents [18].

Globally, a number of synthetic formulations are used as insect and mosquito repellents, the most commonly used synthetic is DEET (N, N-diethyl-metatoluamide). Though a potent repellent, it possesses an unpleasant odour and there are concerns regarding its safety and toxicity when applied to children. These synthetic actives have toxic effects and thus, there is a need to substitute them with the natural insect repellents. Although, several plant-based repellents, like citronella oil, eucalyptus oil, lemongrass, pyrethrum are popularly being used, most evaporate too quickly leaving the user unprotected [19]. This, in turn, has warranted the search for new and effective natural biomolecules to be used as insect repellents. Odalo et al. (2005) tested the topical repellency of some of the essential oil native to Kenya from plants namely, Plectranthus marrubioides, Tetradenia riparia, Conyza newii, Lippia javanica, Tarchonanthus camphoratus and found the oils to repel mosquitoes better than DEET under their experimental conditions (forearm exposure, $3 \mathrm{~min}$ ) [20]. The effectiveness of hydrogenated $N$. cataria oil enriched in dihydro-nepetalactone isomers as insect and mosquito repellents which are as effective as DEET has been reported [21] [22] [23].

Patience et al. (2018) also tested the stability and acceptability of $N$. cataria essential oil formulated as mosquito repellent lotion that contained 5\% NPL in vegetable oil, almond oil and citronella [22]. They found a high degree of acceptability, good mosquito repellency and low toxic effect among the volunteers in Burundi region of East Africa. The authors proposed a sustainable method to tackle the high incidence of malaria in the region and recommended growing $N$. cataria plants by the local population and producing their own mosquito repellent.

The catmint essential oil from different geographical locations shows wide variation especially in the NPL isomers mentioned above. These differences may be environmental or genetic or dependent on prevalent agricultural practices to that region, disease incidence, drying processes, essential oil extraction techniques etc. [22]. Cultivation studies of catmint have been reported in the US, and Egypt. A study of yield statistics done in New Jersey, US revealed oil content of $0.1 \%-0.2 \%$, the oil yield of $8.9 \mathrm{~kg} / \mathrm{ha}$, biomass yield of $7.7 \mathrm{t}$ dry wt./ha and nepetalactone content of $6.0 \%-73.2 \%$ [24]. In one of the studies done in Burundi, East Africa, essential oil yield of $3 \mathrm{~kg} / \mathrm{t}$ (dry plant matter) was reported [22]. In another study at National Research Centre, Egypt, Ibrahim et al., 2017 reported oil content of $0.22 \%$, the oil yield of $18.93 \mathrm{~L} / \mathrm{ha}$, biomass yield of $8.76 \mathrm{t}$ fresh wt/ ha and nepetalactone content between $22.60 \%-24.67 \%$ [25]. Also, there are two varieties of $N$. cataria reported from the United States: 1) $N$. cataria L. var. "Thaya" - a distinct form of catmint (Nepeta cataria L.), useful in the production of essential oil (0.33\%) [26]; 2) Catnip cultivar "CR9"-a new highly aromatic catnip cultivar with high oil content $(0.80 \%$ on dry wt. basis) and increased lev- 
els of (Z,E)-nepetalactone (1) (87\% - 90\%) [9]. This variety was developed especially for commercial agriculture production having an upright growth habit and increased biomass.

Despite the increased interest in catnip as a natural source of insect and mosquito repellent, only a few studies have been taken up to explore its yield potentials. Although a source of essential oil, large scale production of catmint poses countless challenges because of its low biomass production and oil yields. However, improvement in essential oil and biomass can be achieved by proper selection and systematic breeding programmes.

With this backdrop, the present investigation was undertaken to evaluate existing and improved lines for high essential oil of better quality especially high nepetalactone and cultivar recommendation for commercial farming in India.

\section{Materials and Methods}

\subsection{Germplasm Maintenance and Selection}

The open-pollinated seeds of catmint were procured from Jammu and Kashmir Medicinal Plants Introduction Centre and grown in the research farm at CSIR-Central Institute of Medicinal and Aromatic Plants (CIMAP), Lucknow, India $\left(26.5^{\circ} \mathrm{N}\right.$ and $80.50^{\circ} \mathrm{E}$ ) for two successive years (2018 and 2019) during the growing seasons (January-June). In the first year (2018), 30-days old seedlings were transplanted to the field with a $50 \mathrm{~cm}$ row to row and $40 \mathrm{~cm}$ plant to plant spacing and mass selection was done. The collected seeds were bulked and stored properly. In the next year (2019), the bulked seeds were grown and the crops were raised following the standard cultivation practices. Nineteen individual plants out of a total of 50 were selected based on single plant selection (SPS)/individual plant selection considering the morphological characters like plant vigour, growth and plant height $>50-60 \mathrm{~cm}$ with a bushy canopy for the extraction of oil and further studies.

\subsection{Essential Oil Extraction}

The essential oil was extracted from the fresh herb $(100 \mathrm{~g})$ by hydrodistillation at flowering stage using a Clevenger apparatus [27] [28] in duplicate. The essential oil samples were dried using anhydrous sodium sulphate and stored in amber-coloured glass bottles in a refrigerator until chromatographic analysis.

\subsection{GC and GC/MS Analyses}

The essential oil analysis was carried out using GC-FID and GC-MS techniques. The quantification of the essential oil constituents was done on Centurion Scientific Gas Chromatograph (model CS-5800), equipped with flame ionization detector (FID) and BP-5 fused silica capillary column (5\% phenyl)-polymethylsiloxane stationary phase; $30 \mathrm{~m} \times 0.25 \mathrm{~mm}$ internal diameter; film thickness $0.25 \mu \mathrm{m}$ ). The oven temperature was programmed from $60^{\circ} \mathrm{C}$ to $240^{\circ} \mathrm{C}$ with an increase of $3^{\circ} \mathrm{C} \mathrm{min}{ }^{-1}$ and final hold time of $10 \mathrm{~min}$. The injector and detector temperatures 
were $240^{\circ} \mathrm{C}$ and $250^{\circ} \mathrm{C}$, respectively. Nitrogen was used as carrier gas at $1.0 \mathrm{~mL}$ $\min ^{-1}$. The injection volume was $0.3 \mu \mathrm{L}$ (diluted in hexane: 1:1) with a split ratio of 1:60. The GC-MS analysis was done using a Clarus $680 \mathrm{GC}$ interfaced with a Clarus SQ 8C mass spectrometer of PerkinElmer fitted with Elite-5 MS fused-silica capillary column (5\% phenyl)-polymethylsiloxane stationary phase; $30 \mathrm{~m} \times 0.25$ $\mathrm{mm}$ internal diameter, film thickness $0.25 \mu \mathrm{m}$ ). The oven temperature program was from $60^{\circ} \mathrm{C}$ to $240^{\circ} \mathrm{C}$, at $3^{\circ} \mathrm{C} \mathrm{min}^{-1}$, and programmed to $270^{\circ} \mathrm{C}$ at $5^{\circ} \mathrm{C} \mathrm{min}^{-1}$; injector temperature was $250^{\circ} \mathrm{C}$; transfer line and source temperatures were $220^{\circ} \mathrm{C}$; injection size $0.03 \mu \mathrm{L}$ neat; split ratio $1: 50$; carrier gas $\mathrm{He}$ at $1.0 \mathrm{~mL} \cdot \mathrm{min}^{-1}$; ionization energy $70 \mathrm{eV}$; mass scan range $40-450 \mathrm{amu}$. Identification of the essential oil constituents was done on the basis of retention index (RI), determined with reference to homologous series of $n$-alkanes $\left(\mathrm{C}_{7}-\mathrm{C}_{30}\right)$, MS Library search (NIST and WILEY), and by comparing RI and mass spectral data with the literature [29]. The relative amounts of individual components were calculated based on the relative \% peak areas (FID response), without using a correction factor.

\subsection{Statistical Analyses}

The statistical analysis of the mean data of oil and nepetalactone content was carried out using the Web Based Agricultural Statistics Software Package (Wasp 2.0).

The SPSS v. 21 was used to derive the Pearson's correlation matrix on the basis of individual components of catmint essential oil from 13 countries. Some of the oil profiles from these countries were reported from two or more locations/ populations/chemotypes; so a total of 22 oil profiles were compared. Factor reduction on the basis of principal components using direct oblimin rotation was done followed by plotting of the first two components two dimensionally.

\section{Results and Discussion}

Originally growing wild on the banks of Lidder valley in J \& $\mathrm{K}$ (having a sub-humid, temperate climate at an altitude of $\sim 2200 \mathrm{~m}$ ), the catmint was introduced and grown in the warm, sub-tropical climate of Indo-gangetic plains (Lucknow, with an altitude of $123 \mathrm{~m}$ ). The plant growth of the catmint population in the first year was very poor and non-uniform. This might be attributed to change in niche environmental requirement of the plant. Since the seeds were collected from an open pollinated population thriving on high altitudes, the relative low altitude and high temperature of new environment (Lucknow) might have selected only those genotypes having better adaptability to the new environment. The plant having favourable combination of alleles and selection pressure of the breeders helped this crop in acclimatization into a new agro-climatic zone. Subsequently, we observed variation in growth parameters, such as plant height and plant architecture. Several of the plants were stunted whereas 19 showed luxuriant growth with a height of about $50-60 \mathrm{~cm}$ and a bushy pattern. Figure 1 represents field grown plant at vegetative and flowering stage. On the 


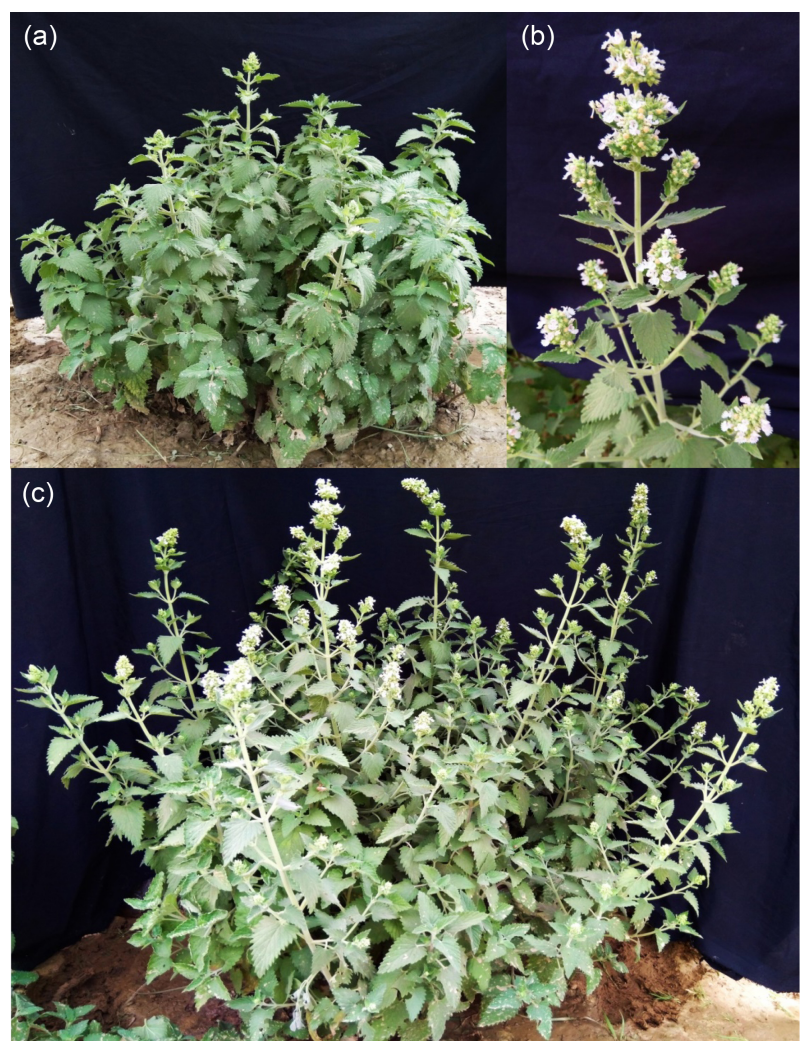

Figure 1. Field-grown catmint ( $N$. cataria) plants at CSIRCIMAP. (a): $N$. cataria: vegetative stage; (b): inflorescence of N. cataria; (c): N. cataria: flowering stage.

basis of the plant growth, we selected nineteen plants for essential oil extraction and chemical analysis by adopting the single plant selection (SPS)/individual plant selection breeding approach.

The essential oil content of the lines at the flowering stage ranged from $0.01 \%$ to $0.20 \%$ (fresh wt. basis) showing a fair degree of variation providing enough scope for selection of promising lines (Coefficient of variation $=52.99 \%)($ Table 1). Line CM12 and CM15 exhibited the highest oil content (0.20\%) and least was recorded in CM04 (0.01\%). Oil accumulation showed variation in the range of $0.01 \%-0.05 \%$ (2 plants); $0.06 \%-0.10 \%$ (11 plants); $0.11 \%-0.15 \%$ (4 plants); and $0.16 \%-0.20 \%$ (2 plants) (Supplementary Figure S2). In one of the reports on Indian catmint grown at $1400 \mathrm{~m}$ (Institute of Himalayan Bioresource Technology, Palampur, Himachal Pradesh, India), the oil yield was found to be $0.4 \%$ (fresh wt. basis) [30]. In a study on Nepeta pogonesperma in Iran, the essential oil and morphological characters were recorded from plants growing at different altitudes [31]. A better essential oil yield and quality at the highest altitude (2800 $\mathrm{m}$ ) was found. They concluded that the light and wind stress in the higher altitudes were responsible for an increase in oil yield and its quality; conversely, heat stress and water deficit in the lower altitudes were the possible causes for reduced oil yield and quality. In our study, the low essential oil yield may be due to the effect of change of altitude and temperature regime on plant growth. 
Table 1. Variation in essential oil content and nepetalactone isomers of $N$. cataria plants grown in Lucknow, India.

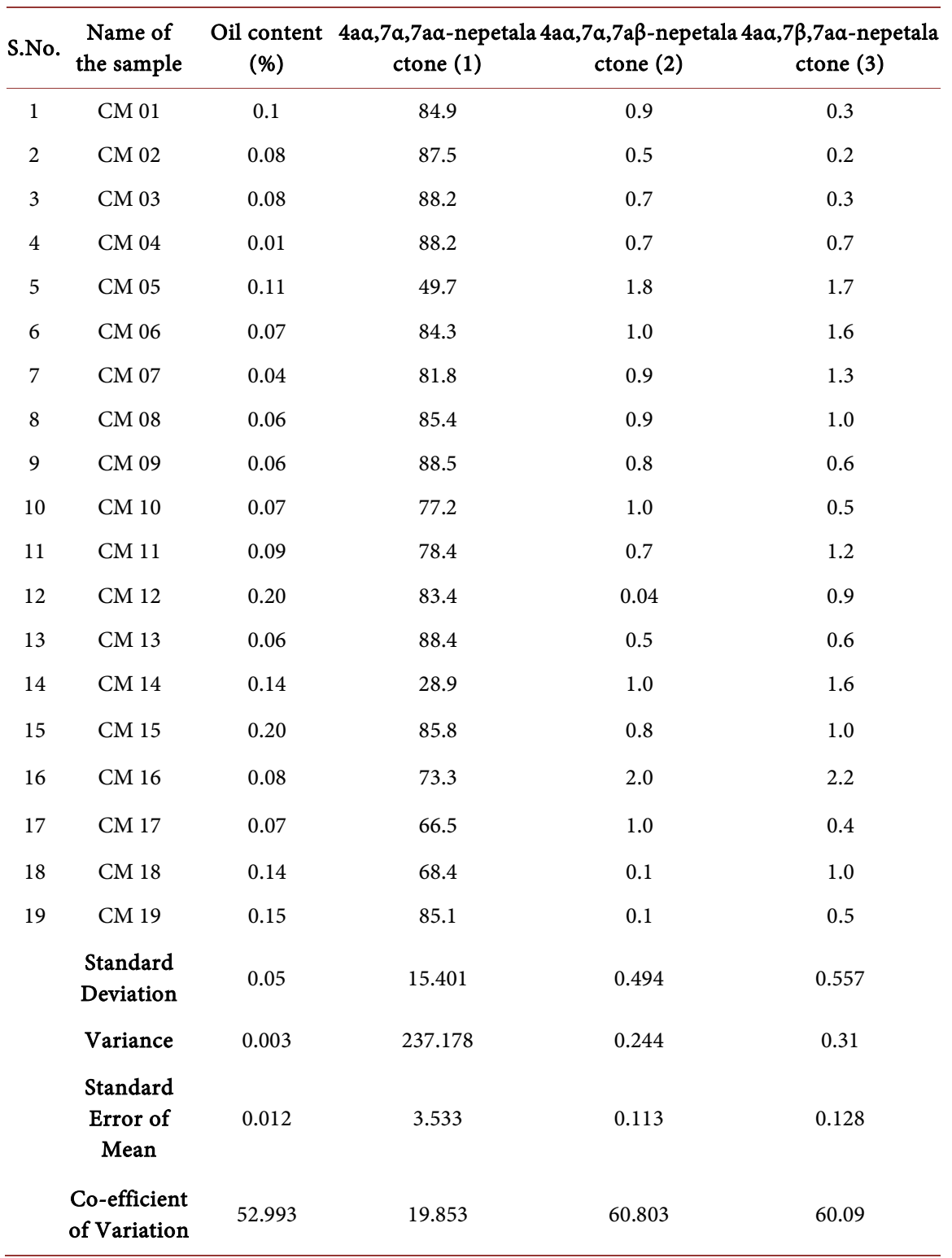

The $N$. cataria oil yield reported by other workers also showed a wide variation from different geographical regions (Table 2). Catmint oil yield (dry wt. basis) from Morocco [32], Iran [33] [34] and Argentina [35] were found to be $1.02 \%, 0.94 \%, 0.9 \%$ and $0.93 \%$, respectively. The highest catmint oil yield (fresh wt. basis) was reported to be $0.25 \%$ from Egypt [25]. They also found the flowering stage to yield maximum oil (0.45\%; dry wt. basis). Different aerial parts yielded essential oil in the following manner: leaves $>$ flowers $>$ stems $>$ and seeds. Hydrodistillation for longer hours resulted in changes in oil profile with more accumulation of lactones and drop in hydrocarbons [36]. In addition, organic solvent extraction resulted in upto $57.24 \mathrm{~g} / \mathrm{kg}$ nepetalactones when ethanol was used as the solvent. 
Table 2. Variation in nepetalactone isomers in $N$. cataria oil.

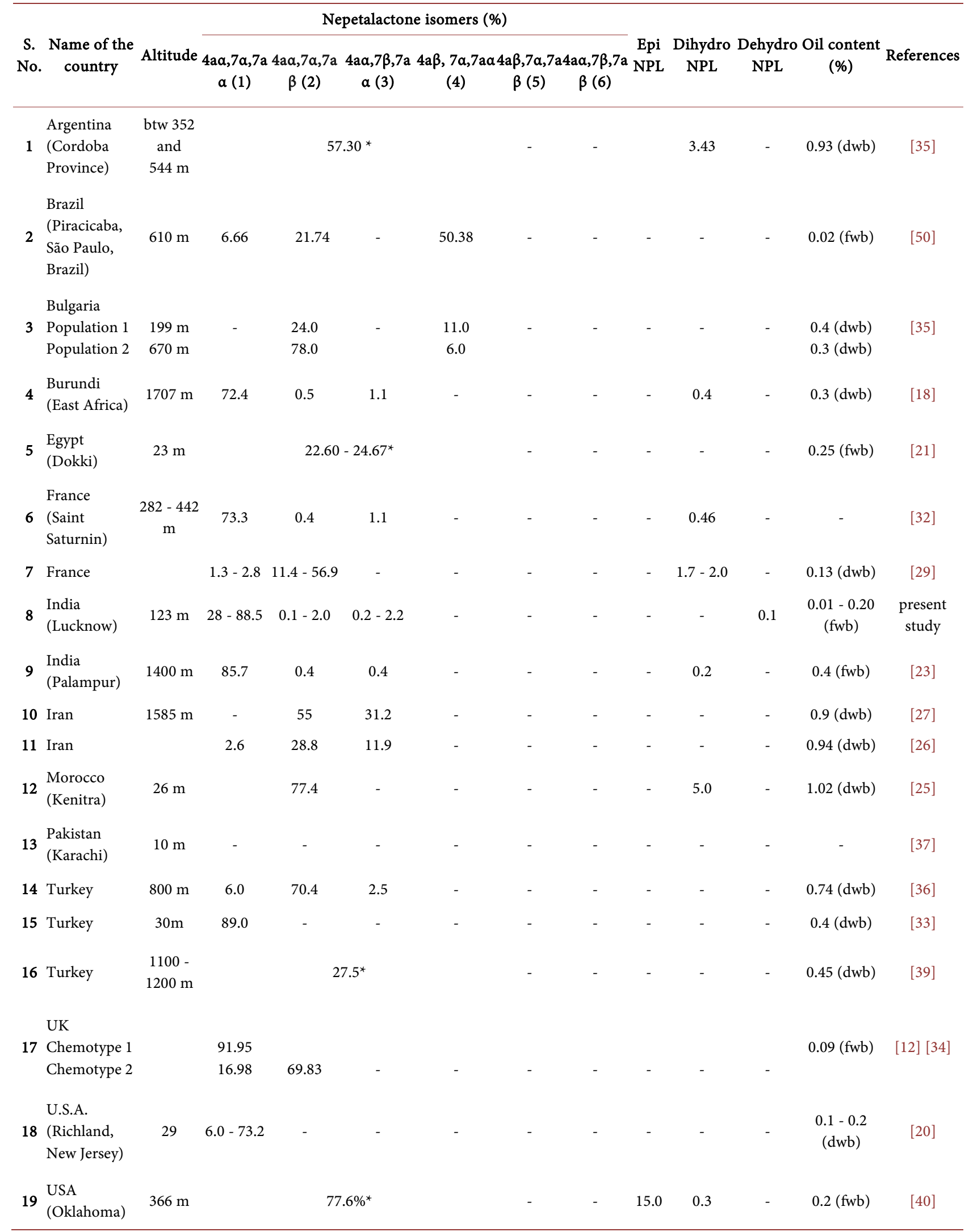

${ }^{*}$ Total nepetalactone content instead of individual isomers, NPL-nepetalactone; dwb-dry weight basis and fwb-fresh weight basis. 


\subsection{Indian Catmint Chemotype Is Rich in $4 a \alpha, 7 \alpha, 7 a \alpha$ NPL Isomer}

The oil was further characterized by GC-MS analysis, which identified 16 compounds, as presented in Table 3 and Supplementary Figure S3. The essential oil of $N$. cataria was found to be dominated by monoterpenes, followed by sesquiterpenes. Among the monoterpenes, acyclic $\{(E)-\beta$-ocimene, lavandulol $\}$, monocyclic (p-cymene, limonene), and bicyclic (4aa,7a,7aa NPL (1), 4a $a, 7 \alpha, 7 \mathrm{a} \beta$ NPL (2), 4a $\alpha, 7 \beta, 7 \mathrm{a} \alpha$ NPL (3), dehydronepetalactone and (E,Z)- iridolactone $\alpha$-pinene, $\beta$-pinene, 1,8-cineole, and trans-pinocarveol) class of compounds were identified as notable constituents. However, identified monocyclic ( $\alpha$-humulene) and bicyclic $\{(\mathrm{E})$ caryophyllene and caryophyllene oxide $\}$ sesquiterpenes accumulated very less in the essential oil (traces, $0.6 \%, 1.7 \%$, respectively).

The Indian catmint essential oil was dominated by one nepetalactone isomer $\{4 a a, 7 a, 7 a a$ NPL (1) $\}$ which was present in the range of $28 \%-88.5 \%$ in the studied lines. The two other NPL isomers identified were $4 \mathrm{a} a, 7 a, 7 \mathrm{a} \beta$ NPL (2) and $4 \mathrm{a} a, 7 \beta, 7 \mathrm{a} \alpha$ NPL (3) present relatively at very low concentrations in the essential oil (in the range of $0.04 \%-2.0 \%$ and $0.2 \%-2.2 \%$, respectively). The oil also showed the presence of dehydronepetalactone. The highest levels of 4a $a, 7 a, 7 \mathrm{a} \alpha$ NPL (1) isomer was identified in line CM09 followed by CM13 $(88.40 \%)>$ CM03 (88.20\%) > CM02 (87.50\%) > CM15 (85.8\%) > and CM08

Table 3. Essential oil composition of the catmint plant as identified by GC-MS.

\begin{tabular}{|c|c|c|c|c|}
\hline S. no. & Name of the compound & $\mathrm{RI}^{\mathrm{a}}$ & $\mathrm{RI}^{\mathrm{b}}$ & Content (\%) \\
\hline 1 & a-Pinene & 934 & 932 & 0.1 \\
\hline 2 & $\beta$-Pinene & 975 & 974 & 0.1 \\
\hline 3 & p-Cymene & 1021 & 1020 & 0.1 \\
\hline 4 & Limonene & 1026 & 1024 & $\mathrm{~T}$ \\
\hline 5 & 1,8-Cineole & 1028 & 1026 & 0.1 \\
\hline 6 & (E)- $\beta$-Ocimene & 1047 & 1044 & $\mathrm{~T}$ \\
\hline 7 & trans-Pinocarveol & 1138 & 1135 & $\mathrm{~T}$ \\
\hline 8 & Lavandulol & 1169 & 1165 & 0.1 \\
\hline 9 & 4a $\alpha, 7 \alpha, 7 \mathrm{a} \alpha-$ Nepetalactone & 1359 & 1357 & 84.3 \\
\hline 10 & $4 \mathrm{a} \alpha, 7 \alpha, 7 \mathrm{a} \beta$-Nepetalactone & 1388 & 1386 & 1.0 \\
\hline 11 & $4 \mathrm{a} \alpha, 7 \beta, 7 \mathrm{a} \alpha-$ Nepetalactone & 1392 & 1391 & 1.6 \\
\hline 12 & (E)-Caryophyllene & 1418 & 1417 & 0.6 \\
\hline 13 & (E,Z)-Iridolactone & 1442 & 1443 & 0.1 \\
\hline 14 & $\alpha$-Humulene & 1454 & 1452 & $\mathrm{~T}$ \\
\hline 15 & Dehydronepetalactone & 1477 & 1470 & 0.1 \\
\hline 16 & Unidentified compound & 1524 & - & 4.7 \\
\hline 17 & Caryophyllene oxide & 1586 & 1582 & 1.7 \\
\hline
\end{tabular}

${ }^{\mathrm{a}}$ Experimental retention index; ${ }^{\mathrm{b}}$ Retention index from literature; t: trace $(<0.05 \%)$. 
(85.4\%). Sufficient variation was present among the lines for nepetalactone content so as to exercise selection between them. Among the nineteen lines taken up for the study, two lines had the $4 \mathrm{a} \alpha, 7 \alpha, 7 \mathrm{a} \alpha$-nepetalactone content of $<50 \%$, two in the range of $51 \%-70 \%, 3$ lines in the range of $71-80 \%$ and 12 lines with more than $80 \%$ nepetalactone content. Similar $4 a \alpha, 7 a, 7 a \alpha$ NPL (1) content $(85.7 \%)$ was reported by Stappen et al., 2015. It is interesting to see that nepetalactone \% was almost same in Indian catmint plants growing at different altitudes, although essential oil yield varied.

\subsection{Nepetalactones in Genus Nepeta}

Nepetalactones serve as biochemical markers of the essential oils of genus Nepeta and are informative biomolecules from a chemotaxonomic point of view [37]. Nepeta species oil exhibits wide chemical polymorphism further compounded by the fact that the oil composition gets influenced by age, climatic conditions, extraction process and analysis method. Asgarpanah et al., 2013 [37] reviewed endemic Iranian Nepeta species and reported presence of 5 NPL isomers-(i) $4 \mathrm{a} \alpha, 7 a, 7 \mathrm{a} \alpha$ NPL (1) (in 14 species); (ii) $4 \mathrm{a} \alpha, 7 \alpha, 7 \mathrm{a} \beta$ NPL (2) (in 8 species); (iii) $4 \mathrm{a} \alpha, 7 \beta, 7 \mathrm{a} \alpha$ NPL (3) (in 2 species); (iv) $4 \mathrm{a} \beta, 7 \alpha, 7 \mathrm{a} \alpha$ NPL (4) (in 8 species); and (v) $4 a \beta, 7 a, 7 a \beta$ NPL (5) (in 10 species).

Genus Nepeta can be subdivided into two groups on the basis of the constitution of essential oil-(i) having predominance of NPL isomers and (ii) those which have compounds other than NPL such as $\beta$-caryophyllene, 1,8 cineole, caryophyllene oxide, citral, etc. as their major constituents [38]. These species accumulate varying amounts of NPL isomers in their essential oil according to different geographical locations and other factors. The essential oil profiles of the species belonging to the two groups have been reported [38] and the variation in NPL isomers of these species has been enlisted in supplementary Table S1. The $4 a \alpha, 7 a, 7 a \alpha$ NPL (1) isomer is dominant in the essential oil of 11 species, out of which the highest accumulators were $N$. caesarea $(91.2 \%-95.3 \%), N$. crassifolia (92.6\%), $N$. cephalotes (90.1\%) and $N$. teydea (89.54\%). Isomer $4 \mathrm{a} \alpha, 7 \boldsymbol{\alpha}, 7 \mathrm{a} \beta \mathrm{NPL}$ (2) was dominant in 14 species and the highest accumulators were $N$. argolica ssp. argolica (68\% - 94.5\%) and $N$. racemosa (31.5\% - 91.6\%). Isomer

$4 a \beta, 7 a, 7 a \alpha$ NPL (4) was dominant in the oils of 6 species with the highest percentage recorded in $N$. eremophila (73.3\%) and $N$. saccharata (66.9\%). Isomer $4 a \beta, 7 \alpha, 7 a \beta$ NPL (5) was dominant in 3 species among which $N$. kotschyi (92.0\%) accumulated the highest percentage. Isomer $4 a \alpha, 7 \beta, 7 a \beta$ NPL (6) was found in only $N$. crassifolia (27.2\%). Isomer $4 \mathrm{a} \alpha, 7 \beta, 7 \mathrm{a} \alpha$ NPL (3) was recorded in 3 species out of which $N$. crassifolia (81.1\%) accumulated the highest. Epinepetalactone was recorded in single species, $N$. mussini (70\%). The species, $N$. tuberosa subsp. tuberose (69\%) recorded highest level of 5, 9-dehydronepetalacone in its essential oil. Trans, trans-nepetalactone was found in 2 species out of which $N$. elliptica (83.4\%) recorded the highest level. Inferring from the above study, isomer $4 \mathrm{a} \alpha, 7 \alpha, 7 \mathrm{a} \beta$ NPL (2) was the dominant nepetalactone in the essential oil 
of majority of the species (14 in numbers) followed by isomer 4aa,7a,7aa NPL (1) which was dominant nepetalactone in 11 species.

\subsection{Nepetalactone Isomers in $N$. cataria Oils}

Increasing interest in plant based molecules as a substitute to synthetic insect repellents has made $N$. cataria L. to be the most extensively studied species in the genus Nepeta. N. cataria oils from plants thriving at different altitudes $(10 \mathrm{~m}$ to $\sim 1700 \mathrm{~m}$ ) having climates ranging from temperate, sub-tropical to tropical in geographical regions around the world have shown highly variable composition, especially in relation to the accumulation of nepetalactone isomers. The oils from Burundi, France [39], India, Turkey [40], UK (chemotype 1) [15] [41] and USA [24] were rich in $4 \mathrm{a} a, 7 a, 7 \mathrm{a} a$ NPL (1) isomer. Oils from Bulgaria [42], France [36], Iran, Morocco, Turkey [43], UK (chemotype 2) [15] [41] were rich in $4 \mathrm{a} \alpha, 7 \alpha, 7 \mathrm{a} \beta$ NPL (2) isomer. The third isomer, $4 \mathrm{a} \alpha, 7 \beta, 7 \mathrm{a} \alpha$ NPL (3), was found in relatively moderate amounts in Iranian oils. The fourth isomer, $4 a \beta$, $7 \alpha, 7 a \alpha$ NPL (4) was found in oils from Brazil and Bulgaria. The fifth and the sixth isomers, $4 a \beta, 7 \alpha, 7 a \beta$ NPL (5) and $4 a \alpha, 7 \beta, 7 a \beta N P L$ (6) were not detected in any of the oils. In addition to these isomers few of the oils had epinepetalactone (15\% in oil from USA); dihydronepetalactone and dehydronepetalactone in low concentration. The oil from Pakistan was found to be devoid of any of the nepetalactones but rich in 1,8-cineole (21.00\%), $\alpha$-humulene (14.44\%), $\alpha$-pinene (10.43\%) and geranyl acetate (8.21\%) [44]. Catmint oil rich in citral derivatives with no nepetalactone was also observed in the oil from Lithuania [45]. The individual components of these catmint oils as reported by their GC-MS profiles were analyzed together. In the Principal Component Analysis (PCA), the first 4 principal components on the basis of Pearson correlation matrix explained the $86.03 \%$ variance among the catmint oils. The $2 \mathrm{D}$ plot of the first two components explained a cumulative variance of $65.42 \%$ (34.95\% and $30.46 \%$, respectively) as shown in Figure 2. The oils grouped according to the presence of individual nepetalactone isomers. The oils from Argentina, Egypt, Turkey [46] and USA [47] clustered with the oil from Pakistan [44]. However, the oil from Pakistan did not have any nepetalactone. The oils from Bulgaria and Brazil showing the presence of $4^{\text {th }}$ nepetalactone isomer were grouped together.

The Indian catmint oil clustered with those of Burundi, France [39], Turkey [40], UK (chemotype 1) [15] [41] and USA [24]. The half-sib progeny of these adapted catmint lines shows sufficient variation that can be treated as a base population for downstream breeding interventions. The lines rich in $4 \mathbf{a} a, 7 \mathbf{a}, 7 \mathrm{a} a$ NPL(1) viz., CM09 (88.50\%), CM05 (88.40\%), CM03 (88.20\%), CM04 (88.20\%) and CM02 (87.50\%) may be considered as elite lines with agronomically desirable traits for development of nepetalactone rich variety (ies). Ours is a preliminary study and the promising results from this needs to be supplemented with experiments involving the study of correlation between the oil content and the nepetalactone content and also the herbage yield of the plant. 


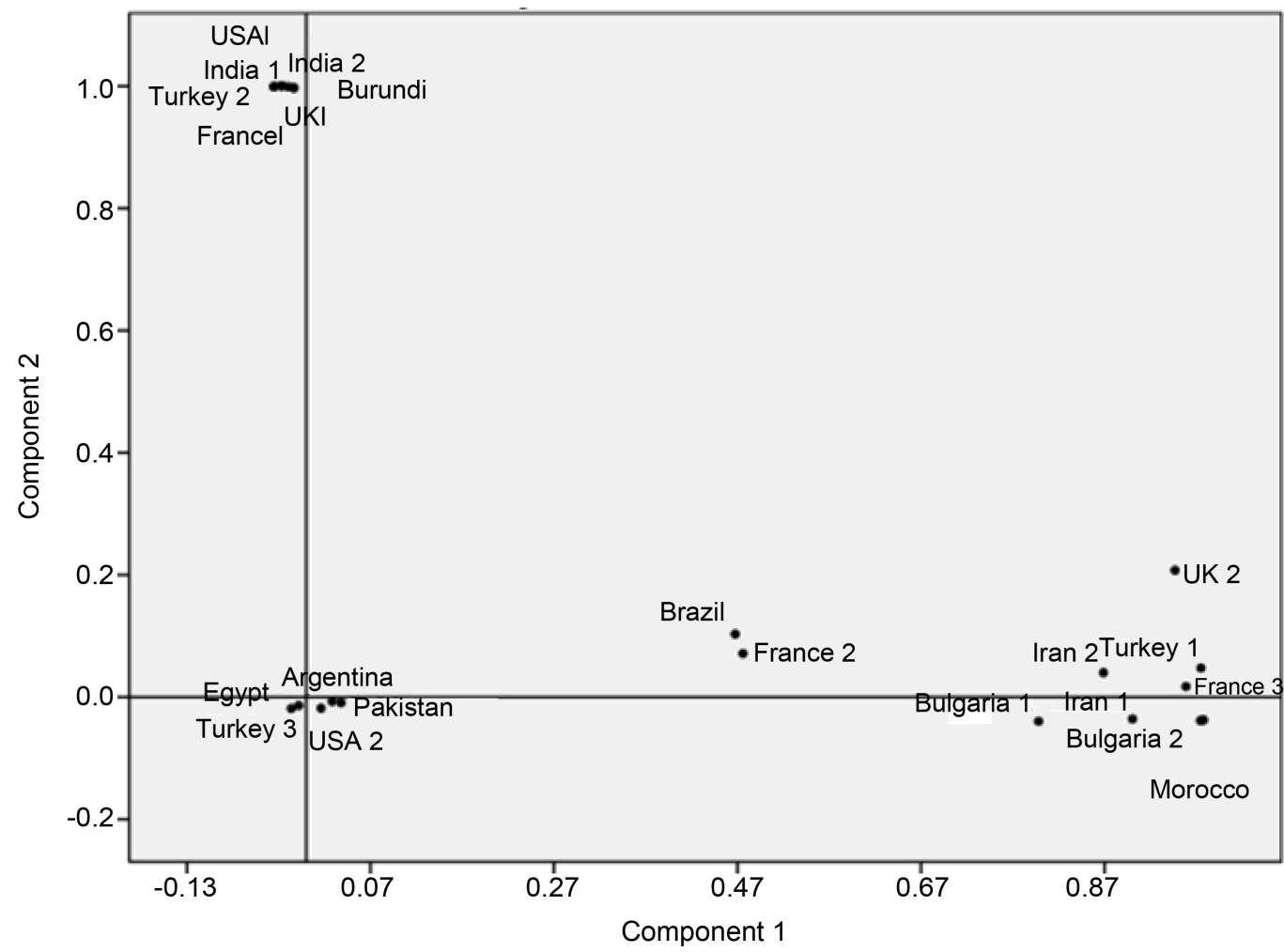

Figure 2. Variability in catmint essential oil by principal component analysis. The essential oil samples depicted in the figure are according to the sample names enlisted in Table 2.

\subsection{Areas that Require R\&D Efforts to Develop Commercial Catmint Cultivars}

The commercialization of catmint as a source of mosquito and insect repellent is still at its infancy. The large scale production of catmint as a source of essential oil remains challenging as it requires improved varieties bred for this application. Focussed breeding approaches (selections, hybridizations, mutagenesis etc.) needs to be attempted for the improvement of the yield-related traits. Hybridization programs are feasible due to the presence of bilabiate bisexual flowers (although small in size) that provide the plant the ability to self-pollinate as well as to outcross. Agrotechnology for its large scale cultivation needs to be developed as a mixed/intercrop leading to further diversification in the list of crop species grown by farmers. As an essential oil yielding crop, this can be a future crop under the umbrella of the Indian government flagship programme, Aroma Mission (https://www.facebook.com/csir.aroma). Under this Mission, cultivation of aromatic crops has been promoted to not only help the farmers economically but also to meet the demands of aroma industry. The insect repellency of the catmint oil can be directly linked to the health sector and holds promise for the prevention of insect transmitted diseases.

The efficacy of insect repellent formulations consisting of a combination of individual nepetalactones as compared to $N$. cataria essential oil should be studied to find an equivalent or more powerful natural substitute to DEET that is 
safe and non-toxic especially to the most vulnerable part of the population i.e., children and pregnant women. Temperature, light and oxidation processes have been found to degrade the essential oil into aldehydes, ketones and alcohols [22]. Detailed studies are required on the photo- and thermostability of the nepetalactones of the essential oil so as to ensure no drop in essential oil quality due to degradation. Composition of the volatiles varied quantitatively when different isolation techniques, such as hydrodistillation (HD), solid phase microextraction (SPME), static headspace (SH) and simultaneous distillation-solvent extraction (SDSE) were used [45]. R\&D to set guidelines for the industry for commercial level extraction and storage of essential oil needs to be taken up.

The nepetalactones are biosynthesized in specialized glandular trichomes on aerial parts of the plant and studies on gland development, nepetalactone biosynthetic pathway genes is necessary to understand and manipulate these pathways for desired oil quality. Studies on types of trichome development in relation to the genotype, altitude and temperature regimes and accumulation of any specific nepetalactone isomers (if any) will help in better elucidating the biosynthetic pathway as in case of Mentha spp. [48] and Ocimum [49]. Also, molecular diversity in catmint from different geographical regions needs to be ascertained.

Species other than $N$. cataria in the genus Nepeta which accumulate very high \% of individual NPL isomers should be made part of germplasm collections in gene banks and check for their possibilities to be exploited as commercial natural, nontoxic sources of insect repellents.

\section{Conclusion}

There is presently no commercial Indian cultivar of catmint and to the best of our knowledge no breeding studies for improvement of its traits have been reported in India. Since the present study on catmint gave encouraging results, the Indian chemotype rich in nepetalactone could be further improved for yield related traits especially for new agroclimatic zones other than its natural habitats. Further screening may probably lead to identification of more varied and contrasting genotypes/chemotypes which can serve as genetic material for breeding as well as molecular studies.

\section{Acknowledgements}

The authors are grateful to the Director, CSIR-CIMAP, Lucknow, for providing the necessary facilities during the present study. The authors also thank the staff of Central Instrumentation Facility at the institute for the essential oil analysis. Dr. Mohammed Talha is acknowledged for the statistical analysis. The publication committee of CSIR-CIMAP has approved this manuscript as an original research article (CIMAP Publication No.-CIMAP/PUB/2020/OCT/102).

\section{Declaration of Interest}

This statement is to certify that all authors have read and approved the manu- 
script being submitted. The authors wish to state that there is no conflict of interest.

\section{References}

[1] GBIF Secretariat (2019) Nepeta, L. GBIF Backbone Taxonomy. Checklist Dataset.

[2] Blatter, E., Wathen, G.A. and Walli, H.J. (1927) Beautiful Flowers of Kashmir. International Book Distributors, Dehra Dun.

[3] Singh, J.B. and Kachroo, P. (1994) Forest Flora of Pir Panjal Range (Northwestern Himalaya). Bishen Singh Mahendra Pal Singh, Dehradun.

[4] Stewart, R.R., Ali, S.I. and Nasir, E. (1972) An Annotated Catalogue of the Vascular Plants of West Pakistan and Kashmir. Fakhri Printing Press, Karachi.

[5] Hooker, J.D. (1879) Flora of British India, Vol. II. Spottiswoode \& Co., London.

[6] Mukerjee, S.K. (1938) A Revision of the Labiateae of the Indian Empire. Ph.D. Thesis, University of Edinburgh, Edinburgh.

[7] Fernald, M.L. (1950) Gray's Manual of Botany, 8th Edition. American Book Company, New York.

[8] Bhattacharjee, S.K. (2000) Handbook of Medicinal Plants. Aavishkar Publishers, Jaipur.

[9] Simon, J.E. and Reichert, W. (2018) Catnip Cultivar CR9. US Patent, US 2018/0116144 A1.

[10] Duda, S.C., Mărghitaș, L.A., Dezmirean, D.S., Bobiș, O. and Duda, M.M. (2015) Nepeta Cataria-Medicinal Plant of Interest in Phytotherapy and Beekeeping. Hop and Medicinal Plants, 23, 34-38.

[11] Hallahan, D.L. (2004) Fragrance Compound. European Patent. EP 1468064 B1.

[12] Duke, J.A. (2002) Handbook of Medicinal Herbs. CRC Press, Boca Raton. https://doi.org/10.1201/9781420040463

[13] Akhshi, S., Shafaghat, A. and Salehzadeh, J. (2014) Chemical Composition and Antibacterial Activity of the Essential Oil the Leaf of Nepeta Persica. Leonardo Journal of Sciences, 13, 131-138.

[14] Zomorodian, K., Saharkhiz, M.J., Shariati, S., Pakshir, K., Rahimi, M.J. and Khashei, R. (2012) Chemical Composition and Antimicrobial Activities of Essential Oils from Nepeta cataria L. against Common Causes of Food-Borne Infections. International Scholarly Research Notices, 2012, Article ID: 591953. https://doi.org/10.5402/2012/591953

[15] Birkett, M.A., Hassanali, A., Hoglund, S., Pettersson, J. and Pickett, J.A. (2011) Repellent Activity of Catmint, Nepeta cataria, and Iridoid Nepetalactone Isomers against Afro-Tropical Mosquitoes, Ixodid Ticks and Red Poultry Mites. Phytochemistry, 72, 109-114. https://doi.org/10.1016/j.phytochem.2010.09.016

[16] Setzer, W.N. (2016) Catnip Essential Oil: There Is More to It than Making Your Cat Go Crazy. American Journal of Essential Oils and Natural Products, 4, 12-15.

[17] Hatch, R.C. (1972) Effect of Drugs on Catnip (Nepeta cataria)-Induced Pleasure Behavior in Cats. American Journal of Veterinary Research, 33, 143-155.

[18] Jackson, S.C., Manzer, L.E., Schleinitz, H.M., Scialdone, M.A. and Hutchenson, K.W. (2013) Hydrogenation of Catmint Oil. United States Patent No. US 8552210 B2.

[19] Maia, M.F. and Moore, S.J. (2011) Plant-Based Insect Repellents: A Review of Their Efficacy, Development and Testing. Malaria Journal, 10, Article No. S11. 
https://doi.org/10.1186/1475-2875-10-S1-S11

[20] Odalo, J.O., Omolo, M.O., Malebo, H., Angira, J., Njeru, P.M., Ndiege, I.O. and Hassanali, A. (2005) Repellency of Essential Oils of Some Plants from the Kenyan Coast against Anopheles Gambiae. Acta Tropica, 95, 210-218. https://doi.org/10.1016/j.actatropica.2005.06.007

[21] Feaster, J.E., Scialdone, M.A., Todd, R.G., Gonzalez, Y.I., Foster, J.P. and Hallahan, D.L. (2009) Dihydronepetalactones Deter Feeding Activity by Mosquitoes, Stable Flies, and Deer Ticks. Journal of Medical Entomology, 46, 832-840. https://doi.org/10.1603/033.046.0413

[22] Patience, G.S., Karirekinyana, G., Galli, F., Patience, N.A., Kubwabo, C., Collin, G., et al. (2018) Sustainable Manufacture of Insect Repellents Derived from Nepeta cataria. Scientific Reports, 8, Article No. 2235. https://doi.org/10.1038/s41598-017-18141-Z

[23] Schultz, G., Peterson, C. and Coats, J.R. (2006) Natural Insect Repellents: Activity against Mosquitoes and Cockroaches. In: Rimando, A.M. and Duke, S.O., Eds., Natural Products for Pest Management, Vol. 927, American Chemical Society, Washington DC, 168-181. https://doi.org/10.1021/bk-2006-0927.ch013

[24] Park, C.H., Tannous, P., Juliani, H.R., Wu, Q.L., Sciarappa, W.J., VanVranken, R., et al. (2007) Catnip as a Source of Essential Oils. Proceedings of the 6th National Symposium Creating Markets for Economic Development of New Crops and New Uses, Miami, 311-315.

[25] Ibrahim, M.E., El-Sawi, S.A. and Ibrahim, F.M. (2017) Nepeta cataria L, One of the Promising Aromatic Plants in Egypt: Seed Germination, Growth and Essential Oil Production. Journal of Materials and Environmental Science, 8, 1990-1995.

[26] Ganzke, T.S. and Hallahan, D.L. (2016) Nepeta cataria L. Var. “Thaya”. U.S. Patent Application No. 14/544,332.

[27] Clevenger, J.F. (1928) Apparatus for Volatile Oil Determination, Description of New Type. The Journal of the American Pharmaceutical Association (1912), 17, 345-349. https://doi.org/10.1002/jps.3080170407

[28] Guenther, E. (1972) The Essential Oils: Volume Three-Individual Essential Oils of the Plant Families Rutaceae and Labiatae. D. Van Nostrand Company, Inc., New York.

[29] Adams, R.P. (2007) Identification of Essential Oil Components by Gas Chromatography/Mass Spectrometry. Vol. 456, Allured Publishing Corporation, Carol Stream.

[30] Stappen, I., Ali, A., Tabanca, N., Khan, I.A., Wanner, J., Gochev, K.V., et al. (2015) Antimicrobial and Repellent Activity of the Essential Oils of Two Lamiaceae Cultivated in Western Himalaya. Current Bioactive Compounds, 11, 23-30. https://doi.org/10.2174/157340721101150804143954

[31] Layeghhaghighi, M., Hassanpour Asil, M., Abbaszadeh, B., Sefidkon, F. and Matinizadeh, M. (2017) Investigation of Altitude on Morphological Traits and Essential oil Composition of Nepeta Pogonosperma Jamzad and Assadi from Alamut Region. Journal of Medicinal Plants and By-Product, 6, 35-40. https://doi.org/10.22092/jmpb.2017.113148

[32] Zenasni, L., Bouidida, H., Hancali, A., Boudhane, A., Amzal, H., Idrissi, A., et al. (2008) The Essentials Oils and Antimicrobial Activity of Four Nepeta Species from Morocco. Journal of Medicinal Plants Research, 2, 111-114.

[33] Morteza-Semnani, K. and Saeedi, M. (2004) Essential Oils Composition of Nepeta cataria L. and Nepeta crassifolia Boiss. and Buhse from Iran. Journal of Essential Oil Bearing Plants, 7, 120-124. https://doi.org/10.1080/0972-060X.2004.10643376 
[34] Saharkhiz, M.J., Zadnour, P. and Kakouei, F. (2016) Essential Oil Analysis and Phytotoxic Activity of Catnip (Nepeta cataria L.). American Journal of Essential Oils and Natural Products, 4, 40-45.

[35] Malizia, R.A., Molli, J.S., Cardell, D.A. and Retamar, J.A. (1996) Volatile Constituents of the Essential Oil of Nepeta cataria L. Grown in Cordoba Province (Argentina). Journal of Essential Oil Research, 8, 565-567.

https://doi.org/10.1080/10412905.1996.9700691

[36] Bourrel, C., Perineau, F., Michel, G. and Bessiere, J.M. (1993) Catnip (Nepeta cataria L.) Essential Oil: Analysis of Chemical Constituents, Bacteriostatic and Fungistatic Properties. Journal of Essential Oil Research, 5, 159-167.

https://doi.org/10.1080/10412905.1993.9698195

[37] Asgarpanah, J., Sarabian, S. and Ziarati, P. (2014) Essential Oil of Nepeta Genus (Lamiaceae) from Iran: A Review. Journal of Essential Oil Research, 26, 1-12. https://doi.org/10.1080/10412905.2013.851040

[38] Sharma, A. and Cannoo, D.S. (2013) Phytochemical Composition of Essential Oils Isolated from Different Species of Genus Nepeta of Labiatae Family: A Review. Pharmacophore, 4, 181-211.

[39] Heuskin, S., Godin, B., Leroy, P., Capella, Q., Wathelet, J.P., Verheggen, F., et al. (2009) Fast Gas Chromatography Characterisation of Purified Semiochemicals from Essential Oils of Matricaria chamomilla L. (Asteraceae) and Nepeta cataria L. (Lamiaceae). Journal of Chromatography $A, 1216,2768-2775$.

https://doi.org/10.1016/j.chroma.2008.09.109

[40] Baser, K.H.C., Kirimer, N., Kurkcuoglu, M. and Demirci, B. (2000) Essential Oils of Nepeta Species Growing in Turkey. Chemistry of Natural Compounds, 36, 356-359. https://doi.org/10.1023/A:1002832628159

[41] Birkett, M.A. and Pickett, J.A. (2003) Aphid Sex Pheromones: From Discovery to Commercial Production. Phytochemistry, 62, 651-656. https://doi.org/10.1016/S0031-9422(02)00568-X

[42] Handjieva, N.V., Popov, S.S. and Evstatieva, L.N. (1996) Constituents of Essential Oils from Nepeta cataria L., N. grandiflora M.B. and N. nuda L. Journal of Essential Oil Research, 8, 639-643. https://doi.org/10.1080/10412905.1996.9701032

[43] Adiguzel, A.H.M.E.T., Ozer, H., Sokmen, M., Gulluce, M.E.D.I.N.E., Sokmen, A., Kilic, H., et al. (2009) Antimicrobial and Antioxidant Activity of the Essential Oil and Methanol Extract of Nepeta cataria. Polish Journal of Microbiology, 58, 69-76.

[44] Gilani, A.H., Shah, A.J., Zubair, A., Khalid, S., Kiani, J., Ahmed, A., et al. (2009) Chemical Composition and Mechanisms Underlying the Spasmolytic and Bronchodilatory Properties of the Essential Oil of Nepeta cataria L. Journal of Ethnopharmacology, 121, 405-411. https://doi.org/10.1016/j.jep.2008.11.004

[45] Baranauskiene, R., Venskutonis, R.P. and Demyttenaere, J.C. (2003) Sensory and Instrumental Evaluation of Catnip (Nepeta cataria L.) Aroma. Journal of Agricultural and Food Chemistry, 51, 3840-3848. https://doi.org/10.1021/jf021187b

[46] Kilic, O., Behcet, L. and Bagci, E. (2013) Essential Oil Compounds of Three Nepeta L. Taxa from Turkey, and Their Chemotaxonomy. Asian Journal of Chemistry, 25, 8181-8183. https://doi.org/10.14233/ajchem.2013.15531

[47] Regnier, F.E., Waller, G.R. and Eisenbraun, E.J. (1967) Studies on the Composition of the Essential Oils of Three Nepeta Species. Phytochemistry, 6, 1281-1289. https://doi.org/10.1016/S0031-9422(00)86090-2

[48] Turner, G.W., Gershenzon, J. and Croteau, R.B. (2000) Distribution of Peltate Glandular Trichomes on Developing Leaves of Peppermint. Plant Physiology, 124, 
655-664. https://doi.org/10.1104/pp.124.2.655

[49] Maurya, S., Chandra, M., Yadav, R.K., Narnoliya, L.K., Sangwan, R.S., Bansal, S., et al. (2019) Interspecies Comparative Features of Trichomes in Ocimum Reveal Insights for Biosynthesis of Specialized Essential Oil Metabolites. Protoplasma, 256, 893-907. https://doi.org/10.1007/s00709-018-01338-y

[50] Ricci, E.L., Toyama, D.O., Lago, J.H.G., Romoff, P., Kirsten, T.B., Reis-Silva, T.M. and Bernardi, M.M. (2010) Anti-Nociceptive and Anti-Inflammatory Actions of Nepeta cataria L. var. Citriodora (Becker) Balb. Essential Oil in Mice. Journal of the Health Sciences Institute, 28, 289-293. 


\section{Supplementary Material}

Table S1. List of species of Nepeta containing nepetalactone as major constituent in its essential oil.

\begin{tabular}{|c|c|c|c|c|c|c|c|c|}
\hline S. No. & Name of the species & $A(1)$ & B (2) & C (4) & $\mathrm{D}(5)$ & $\mathrm{E}(6 / 3)$ & $\mathrm{F}$ & G \\
\hline 1 & N. caesarea (i) & $91.2-95.3$ & - & - & - & - & - & - \\
\hline 2 & N. caesarea (ii) & $92-95$ & - & - & - & - & - & - \\
\hline 3 & $N$. teydea a) Leaves (before flowering) & 89.54 & - & - & - & - & - & - \\
\hline 4 & $N$. persica (aerial parts) & 80 & - & - & - & - & - & - \\
\hline 5 & N. cadmea (i) (herbal parts) & 74.96 & - & - & - & - & - & - \\
\hline 6 & N. $x$ faassenii (dry leaves) & 67.8 & - & - & - & - & $-/ 2.3$ & - \\
\hline 7 & N. racemosa & 64.9 & 7.4 & 1.7 & - & - & - & - \\
\hline 8 & $N$. assurgens & 44.6 & 2.8 & - & - & - & - & - \\
\hline 9 & N. cadmea (ii) (herbal parts) & 44.51 & - & - & - & - & - & - \\
\hline 10 & N. cephalotes (i) & 35.1 & - & - & - & - & - & - \\
\hline 11 & N. govaniana & 25.9 & - & - & - & - & - & - \\
\hline 12 & N. teydea b) Leaves and flowers & - & - & - & - & - & - & - \\
\hline 13 & $N$. argolica ssp argolica & - & $68-94.5$ & - & - & - & - & - \\
\hline 14 & N. racemosa & - & $31.5-91.6$ & - & - & - & - & - \\
\hline 15 & N. rtanjensis (i) (aerial parts) & - & 86.4 & 6.3 & - & - & - & - \\
\hline 16 & N. meyeri (aerial parts) & 8.83 & 83.4 & - & - & - & - & - \\
\hline 17 & N. rtanjensis (ii) (aerial parts) & - & 79.9 & - & - & - & - & - \\
\hline 18 & $N$ cataria i) whole plant & - & 77.4 & - & - & - & - & - \\
\hline 19 & N. tuberose (whole plant) & - & 76.8 & - & - & - & - & - \\
\hline 20 & N. nuda ssp nuda b) verticillaster oil & - & 75.7 & - & - & - & - & - \\
\hline 21 & N. atlantica (whole plant) & - & 71.4 & - & - & - & - & - \\
\hline 22 & $N$ cataria ii) leaves & 6 & 70.4 & - & - & $-/ 2.5$ & - & - \\
\hline 23 & N. nepetella ssp aragonensis & 3.5 & 57.7 & - & - & - & - & - \\
\hline 24 & $N$. granatensis (whole plant) & - & 39.4 & - & - & - & - & - \\
\hline 25 & N. transcaucasica (aerial parts) & 28 & 39 & - & - & - & - & - \\
\hline 26 & N. nuda ssp albiflora & 37.6 & 37.6 & - & - & - & - & - \\
\hline 27 & $\mathrm{~N}$ cataria iii) & - & 28.8 & 11.9 & - & - & - & - \\
\hline 28 & N. nuda ssp nuda a) leaves oil & - & 24.7 & - & - & - & - & - \\
\hline 29 & N. septemcrenata (aerial parts) & 19.2 & 24.2 & - & - & - & - & - \\
\hline 30 & N. parnassica a) Vegetative stage & 1.5 & 22 & - & - & 7.9 & - & - \\
\hline 31 & N. coerulea & 11.9 & 21.5 & 3.7 & 19.3 & - & - & - \\
\hline 32 & N. parnassica b) Flowering stage & 17.3 & 8.9 & - & - & 2.0 & - & - \\
\hline 33 & N. eremophila (aerial parts) & - & - & 73.3 & - & - & - & - \\
\hline 34 & N. saccharata (aerial parts) & - & - & 66.9 & - & - & - & - \\
\hline 35 & $N$. persicac) stem & - & 24.9 & 66.2 & - & - & - & - \\
\hline
\end{tabular}




\section{Continued}

\begin{tabular}{|c|c|c|c|c|c|c|c|c|}
\hline 36 & $N$. bornmuelleri (aerial parts) & - & - & 64 & - & - & - & - \\
\hline 37 & $N$. persica b) leaf & - & 28.3 & 62.3 & - & - & - & - \\
\hline 38 & $N$. persica a) flower & - & 33 & 58.5 & - & - & - & - \\
\hline 39 & N. racemosa (aerial parts) & 24.4 & 25.6 & 33.6 & - & - & - & - \\
\hline 40 & $N$. persica d) root & - & 7.6 & 27.1 & - & - & - & - \\
\hline 41 & N. sintenissii (aerial parts) & - & - & 23.4 & - & - & - & - \\
\hline 42 & N. kotschyi (aerial parts) & - & - & - & 92 & - & - & - \\
\hline 43 & N. grandiflora & - & 2.4 & - & 41 & - & - & - \\
\hline 44 & $N$. argolica & 26.5 & 12.9 & 14.5 & 29.4 & - & - & - \\
\hline 45 & N. crassifolia & 16.3 & 7.7 & 9.6 & - & $27.2 /-$ & - & - \\
\hline 46 & N. crassifolia & - & - & 5.9 & - & $-/ 81.1$ & - & - \\
\hline 47 & $N$. betonicifolia (aerial parts) & - & - & - & - & $-/ 42$ & - & - \\
\hline 48 & N.nuda & - & - & - & - & $-/ 18.10$ & - & - \\
\hline 49 & N. cataria i) & - & - & - & - & - & $>77 /-$ & - \\
\hline 50 & N. nepetella (leaves and flowers) & - & - & - & - & - & $76.5 /-$ & - \\
\hline 51 & $N$. angustifaliathe & - & - & - & - & - & $75.37 /-$ & - \\
\hline 52 & N. mahanensis (aerial parts) & - & - & - & - & - & $37.6 /-$ & - \\
\hline 53 & N. cataria ii (aerial parts) & - & - & - & - & - & $27.5 /-$ & - \\
\hline 54 & N. mussini & - & - & - & - & - & $-/ 70$ & - \\
\hline 55 & N. tuberosa subsp. tuberose (inflorescence) & - & - & - & - & - & - & $69 /-$ \\
\hline 56 & N. elliptica (aerial parts) & - & - & - & - & - & - & $-/ 83.4$ \\
\hline 57 & $N$. cataria (leaves) & - & - & - & - & - & - & $-/ 50.38$ \\
\hline
\end{tabular}

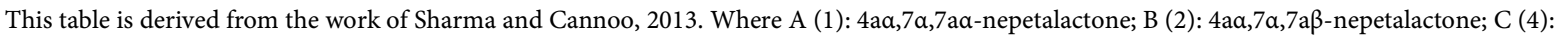
$4 a \beta, 7 \alpha, 7 a \alpha-n e p e t a l a c t o n e ; ~ D ~(5): ~ 4 a \beta, 7 \alpha, 7 a \beta$-nepetalactone; E (6/3): 4a $, 7 \beta, 7 a \beta$-nepetalactone/4a $\alpha, 7 \beta, 7 a \alpha$-nepetalactone; F: nepetalactone/epinepetalactone; G: 5,9-dehydronepetalacone/(7R)-trans, trans-nepetalactone.

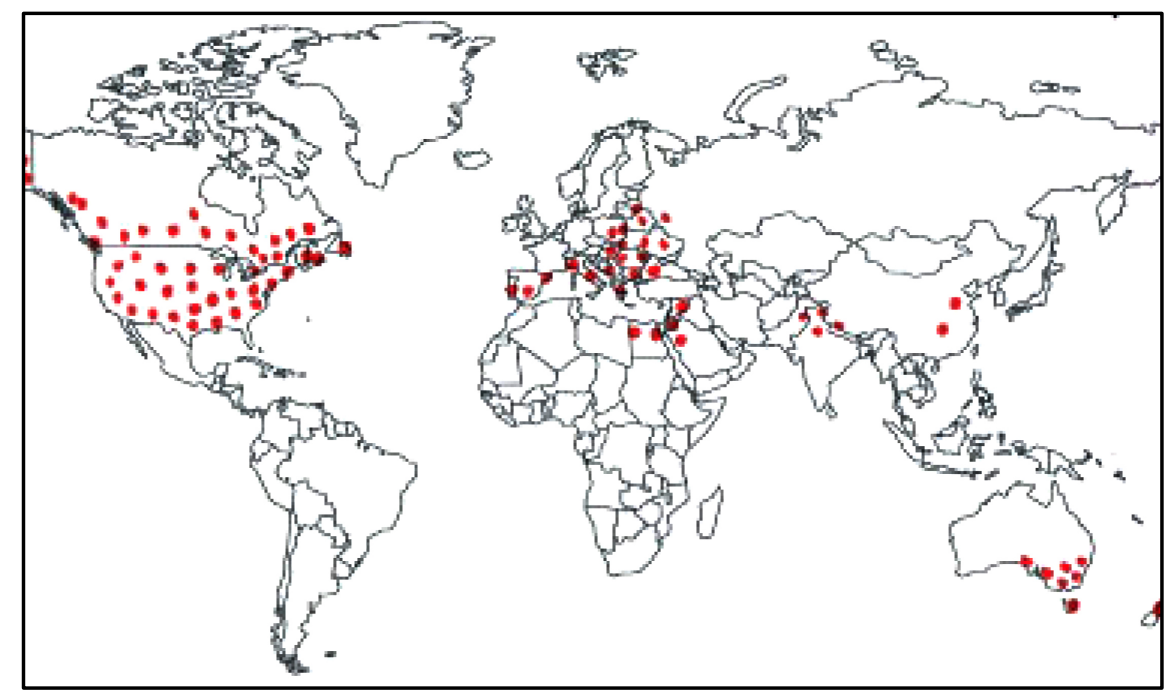

Figure S1. Geographical distribution of catmint natural population. 


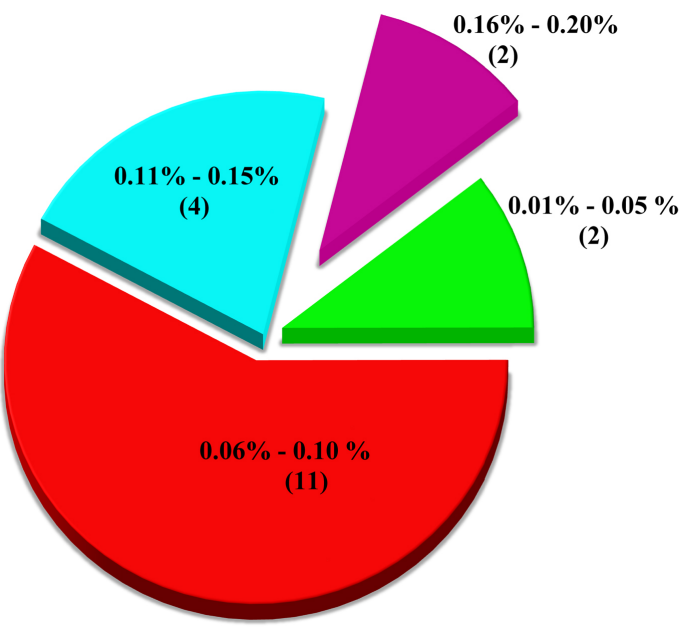

Figure S2. Variation of essential oil content in $N$. cataria lines. Different colours denote ranges of essential oil content. Number in paranthesis denote number of plants in each range.

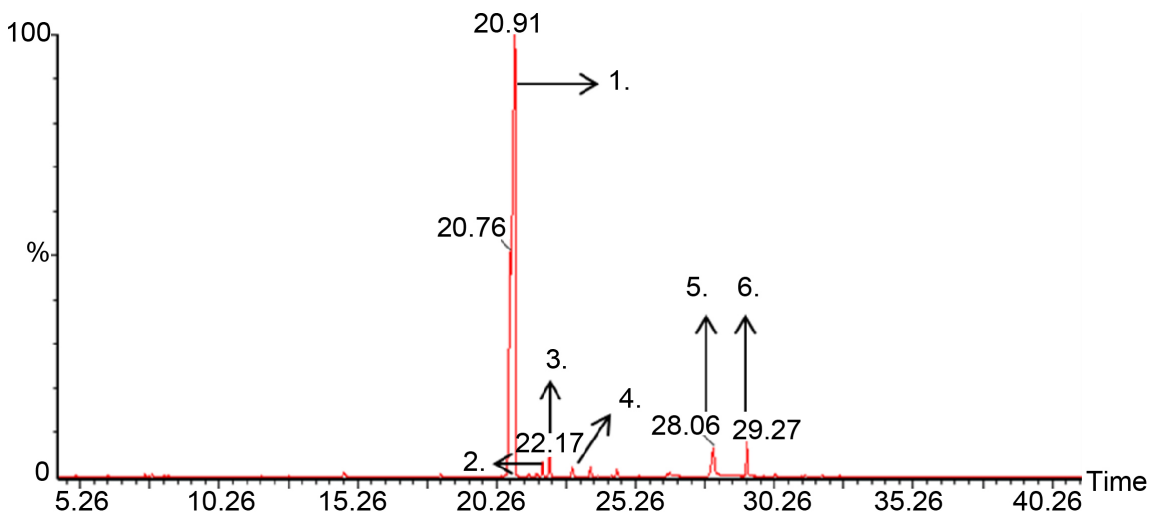

Figure S3. GC-MS profile of CM06 showing 4aa,7a,7aa-nepetalactone and other components of catmint oil. The oil components numbered 1-6 are as follows: 1 .

4a $\alpha, 7 \alpha, 7 \mathrm{a} \alpha$-nepetalactone; 2. 4aa,7a,7a $\beta$-nepetalactone; 3. 4a $\alpha, 7 \beta, 7 \mathrm{a} \alpha$-nepetalactone; 4. (E)-Caryophyllene; 5. Unidentified compound; 6. Caryophyllene oxide. 